\title{
Individual contributions of Savinase and Lactobacillus plantarum to lentil functionalization during alkaline $\mathrm{pH}$-controlled fermentation
}

\author{
Sara Bautista-Expósito ${ }^{\mathrm{a}}$, Elena Peñas ${ }^{\mathrm{a}}$, Montserrat Dueñas ${ }^{\mathrm{b}}$, José Manuel Silván ${ }^{\mathrm{a}}$, Juana Frias ${ }^{\mathrm{a}}$, \\ Cristina Martínez-Villaluenga ${ }^{\text {a,* }}$ \\ ${ }^{a}$ Institute of Food Science, Technology and Nutrition (ICTAN-CSIC), Juan de la Cierva 3, 28006 Madrid, Spain \\ ${ }^{\mathrm{b}}$ Research Group on Polyphenols, Nutrition and Bromatology Unit, Faculty of Pharmacy, University of Salamanca, Campus Miguel Unamuno, 37007 Salamanca, Spain
}

\section{A R T I C L E I N F O}

\section{Keywords:}

Lentil

pH-controlled fermentation

Peptides

Phenolic compounds

Bioactivity

Metabolic syndrome

Savinase

L. plantarum

\begin{abstract}
A B S T R A C T
Legumes offer the possibility to develop multifunctional foods with benefits for metabolic syndrome. Our objective was to study the effect of alkaline fermentation by Lactobacillus plantarum and Savinase (FLPS) as well the individual effects of both processes on peptides, phenolics and bioactivity of lentil. FLPS increased peptides and some flavonoids and enhanced antioxidant activity, inhibition of angiotensin I-converting enzyme (ACE) and intestinal maltase activities of lentil soluble fraction. Savinase contributed to peptide release, ACE inhibitory and antioxidant activities of lentil soluble fraction. $L$. plantarum affected to phenolic composition, $\alpha$-glucosidase and lipase inhibitory activities. Mass spectrometry analysis of the most active fermented lentil subfraction allowed the identification of the main bioactive compounds. Gastrointestinal digestion of fermented lentil increased bioaccessibility of peptides and phenolics as well as antioxidant activity. FLPS enhanced the overall healthy potential of lentil offering the possibility of its use as strategy for lentil functionalization.
\end{abstract}

\section{Introduction}

Unhealthy life style has raised the risk of population for non-communicable diseases which are the leading cause of death and disability globally (World Health Organization, 2014). In this context, regular physical activity and healthy diets combined with the intake of functional foods may help minimizing or even preventing certain chronic diseases (Jew, AbuMweis, \& Jones, 2009). Functional foods are commonly designed to reach one physiological target. Nowadays, the knowledge on the multifactorial origin of many chronic diseases provides a new framework for the development of multifunctional foods.

As a legume, lentil (Lens culinaris Medik.) provides excellent nutritional quality and an array of functional compounds, including phenolics (Zhang et al., 2015) and bioactive peptides (Garcia-Mora et al., 2017). Lentil bioactive compounds are known to bind physiological targets to affect various signaling processes or regulatory functions that can lead to health benefits. For instance, lentil phenolic compounds have demonstrated a potential health benefit for lipid and glucose homeostasis as these compounds are able to inhibit gastrointestinal enzymes involved in carbohydrate ( $\alpha$-glucosidase) and lipid digestion (pancreatic lipase) (Zhang et al., 2015). Otherwise, lentil peptides derived from $11 \mathrm{~S}$ and $7 \mathrm{~S}$ globulins are able to bind angiotensin I-converting enzyme (ACE) and scavenge reactive oxygen species (ROS) in vitro (Garcia-Mora et al., 2017). All these studies position lentil on the market as a promising and reliable raw material in multifunctional food development.

Bioprocessing is a research area with potential application to exploit the functional properties of legumes. In particular, enzymatic hydrolysis with food-grade alkaline serine proteases from Bacillus spp. has been used to produce lentil and pinto bean functional hydrolysates rich in antioxidant and ACE-inhibitory peptides and phenolic compounds (Garcia-Mora, Peñas, Frias, \& Martinez-Villaluenga, 2014; 2015). Fermentation is also a well-designed biotechnology for manufacturing functional foods (Filannino, Di Cagno, \& Gobetti, 2018). Metabolic features of lactic acid bacteria may improve the bioavailability and bioactivity of phytochemicals and peptides with beneficial consequences for human health. For instance, fermentation with Lactobacillus plantarum (FLP) has shown to increase free phenolic compounds and the antioxidant and antihypertensive potential of lentil flour (Torino et al., 2013). More recently, it has been observed that common bean fermentation by L. plantarum $299 \mathrm{v}$ enhances the release of peptides able to bind gut enzymes including intestinal $\alpha$-glucosidase, pancreatic lipase and $\boldsymbol{\alpha}$-amylase (Jakubczyk, Karas, Zlotek, Szymanovska, 2017). Combination of proteolytic microbial strains and commercial enzymes is an alternative strategy used to functionalize milk fermented products as reviewed by Hafeez et al. (2014); however,

\footnotetext{
* Corresponding author at: C/ Juan de la Cierva, 3, 28006, Madrid, Spain

E-mail address: c.m.villaluenga@csic.es (C. Martínez-Villaluenga).
} 
it has not been explored in legumes. Microbial and commercial enzymes may act synergistically increasing peptide content and diversifying the bioactivity of fermented products.

In this research, we aimed to further investigate the impact of fermentation with $L$. plantarum CECT 748 and enzymatic hydrolysis by Savinase 16 L (FLPS) on bioaccessibility of peptides and phenolics as well as multifunctional properties of lentil. The individual effects of FLP and hydrolysis with Savinase (HS) were also examined to evaluate their contribution when they are used in combination. As far as we know, a similar quantitative approach has not been published yet and is, therefore, one of the merits of this study. Our second objective was to identify bioactive compounds through fractionation and bioassayguided selection of the most multiactive fraction. Gastrointestinal digestion (GD) has been shown to modify peptide and phenolic composition of foods and as consequence their health benefits (LuzardoOcampo et al., 2017). As such, it is important that any bioactive peptide or phenolic compound released by fermentation should be resistant to GD so as to reach the physiological targets in an active form. Thus, in this study, the impact of simulated GD on peptide and phenolic content as well as the bioactivity of lentil soluble fraction was studied.

\section{Materials and methods}

\subsection{Materials}

Lentil seeds (Lens culinaris Medik. var. Castellana) were purchased from Semillas Iglesias S.A. (Salamanca, Spain), milled (Moulinex, Allençon, France), passed through a 60 -mesh sieve with $0.5 \mathrm{~mm}$ pore size and stored at $4{ }^{\circ} \mathrm{C}$ until use. A commercial food grade protease Savinase ${ }^{\circledR} 16$ L (16 KNPU/g) was provided by Novozyme (Bagsvaerd, Denmark). L. plantarum CECT 748 was purchased from the Spanish Type Culture Collection (CECT, Valencia, Spain). MidiTrap ${ }^{\mathrm{TM}}$ G10 gel filtration columns were from GE Healthcare (Barcelona, Spain). Enzymes used including ACE (EC 3.4.15.1), rat intestine $\alpha$-glucosidase (EC 3.2.1.20), porcine pancreatic lipase type II (EC 3.1.1.3), pepsin from porcine gastric mucosa (EC 3.4.23.1), pancreatin from porcine pancreas (EC 232-468-9) as well as other chemicals were purchased from Sigma-Aldrich (Madrid, Spain) unless otherwise stated.

\subsection{Techniques used for lentil processing}

The following three processing techniques were implemented on lentil flour:

HS. Lentil flour was suspended in $1.5 \mathrm{~L}$ of sterile tap water $(143 \mathrm{~g} / \mathrm{L}$ final concentration), equilibrated at $37^{\circ} \mathrm{C}$ and the $\mathrm{pH}$ adjusted to 8.5 with $1 \mathrm{M} \mathrm{NaOH}$. Enzymatic hydrolysis was performed in a $3 \mathrm{~L}$ Bioflo/ Celligen 115 bioreactor (Eppendorf Iberica, Madrid, Spain) with continuous stirring $(300 \mathrm{rpm})$ and the addition of Savinase $(365 \mathrm{mg} / \mathrm{L}$ final concentration) at $37^{\circ} \mathrm{C}$ and $\mathrm{pH} 8.5$ for $15 \mathrm{~h}$.

FLP. One cryovial of $L$. plantarum CECT 748 was propagated using Man Rogosa Sharpe (MRS) broth (Pronadisa, Madrid, Spain) as described previously (Limon et al., 2015). After propagation, cells were harvested by centrifugation at $8000 \times g$ for $10 \mathrm{~min}$, washed twice, and suspended in sterile water at the minimum cell density of $8 \log \mathrm{CFU} /$ mL. Fermentation was carried out in a $3 \mathrm{~L}$ Bioflo/Celligen 115 bioreactor (Eppendorf Iberica, Madrid, Spain) mixing $1.5 \mathrm{~L}$ of sterile tap water with lentil flour ( $143 \mathrm{~g} / \mathrm{L}$ final concentration) and $L$. plantarum $\left(2 \times 10^{8} \mathrm{CFU} / \mathrm{L}\right.$ final cell density) under stirring conditions $(300 \mathrm{rpm})$ at $37^{\circ} \mathrm{C}, \mathrm{pH} 8.5$ for $15 \mathrm{~h}$.

FLPS. Starter culture was prepared as described above. L. plantarum $\left(2 \times 10^{8} \mathrm{CFU} / \mathrm{L}\right.$ final cell density), Savinase $(365 \mathrm{mg} / \mathrm{L}$ final concentration) and lentil flour ( $143 \mathrm{~g} / \mathrm{L}$ final concentration) were used to prepare a $1.5 \mathrm{~L}$ fermented flour suspension in a $3 \mathrm{~L}$ Bioflo/Celligen 115 bioreactor (Eppendorf Iberica, Madrid, Spain) with a continuous speed mixer $(300 \mathrm{rpm})$ at $37^{\circ} \mathrm{C}, \mathrm{pH} 8.5$ for $15 \mathrm{~h}$.

Three independent replicates were conducted for each treatment.
Soluble fractions from all samples were obtained by centrifugation at $7500 \times g$ at $5{ }^{\circ} \mathrm{C}$ for $15 \mathrm{~min}$. Supernatants were stabilized by heating at $70{ }^{\circ} \mathrm{C}$ during $10 \mathrm{~min}$ for enzymatic and microbial inactivation. Soluble fraction from unfermented lentil flour was used as control. Finally, all samples were freeze-dried and stored under vacuum at $-20^{\circ} \mathrm{C}$ until use.

\subsection{Fractionation of lentil soluble fraction by size exclusion chromatography}

FLPS soluble fraction was subjected to size exclusion chromatography using MidiTrap ${ }^{\mathrm{TM}}$ G10 columns containing Sephadex G-10 in which molecules are separated on the basis of differences in size. Freeze-dried sample was dissolved in distilled water $(20 \mathrm{mg} / \mathrm{mL})$ and filtered through $0.45 \mu \mathrm{m}$ syringe filters. Column was equilibrated with $8 \mathrm{~mL}$ of deionized water. A sample volume of $0.3 \mathrm{~mL}$ followed by $0.3 \mathrm{~mL}$ of deionized water were added to the column allowing entering the packed bed completely and discarding the flow-through. Elution was carried out adding $2.5 \mathrm{~mL}$ of deionized water to the column and collecting five fractions (F1 to F5) containing $0.5 \mathrm{~mL}$ of eluate. Finally, collected fractions were lyophilized and stored at $-20^{\circ} \mathrm{C}$ until analysis.

\subsection{In vitro GD of lentil samples simulating physiological conditions}

FLPS soluble fraction was subjected to a sequential gastric and duodenal digestion according to the method described by Garcia-Mora et al. (2014). Briefly, FLPS was dissolved in simulated gastric fluid (SGF, $0.15 \mathrm{M} \mathrm{NaCl}$; pH 2.5). Samples were pre-heated for $15 \mathrm{~min}$ at $37^{\circ} \mathrm{C}$. Then $400 \mu \mathrm{L}$ of a solution containing $0.59 \%(\mathrm{w} / \mathrm{v})$ pepsin $(3640$ $\mathrm{U} / \mathrm{mg}$ protein) in SGF were added and the $\mathrm{pH}$ was adjusted to 2.5 with $0.01 \mathrm{M} \mathrm{HCl}$. Digestion was performed at $37^{\circ} \mathrm{C}$ for $2 \mathrm{~h}$ and subsequently stopped by increasing the $\mathrm{pH}$ to 7.5 with $0.1 \mathrm{M} \mathrm{NaOH}$. Gastric digest were adjusted to $\mathrm{pH}$. 6.5 with $0.01 \mathrm{M} \mathrm{HCl}$. In order to simulate a duodenal environment the following solutions were added: $150 \mu \mathrm{L}$ of a bile salt mixture containing equimolar quantities $(0.125 \mathrm{M})$ of sodium taurocholate and glycodeoxycholic acid, $46 \mu \mathrm{L}$ of $1 \mathrm{M} \mathrm{CaCl}_{2}, 500 \mu \mathrm{L}$ of $0.25 \mathrm{M}$ Bis-Tris (pH 6.5), and $100 \mu \mathrm{L}$ of pancreatin in SGF at pH 7.0. Digestion was carried out at $37^{\circ} \mathrm{C}$ for $2 \mathrm{~h}$. Finally, pancreatin was inactivated by heating at $80^{\circ} \mathrm{C}$ for $15 \mathrm{~min}$.

\subsection{Determination of peptide and total phenolic compounds contents}

Peptide concentration was measured by Pierce Quantitative Colorimetric Peptide Assay kit (Fisher Scientific, Madrid, Spain) in permeates obtained by ultrafiltration through cellulose membranes of $10 \mathrm{kDa}$ pore size (Millipore, Billerica, MA, USA). Results were expressed as mg of peptides/g of soluble fraction. Total phenolic compounds were determined using the Folin-Ciocalteau method as previously described (Garcia-Mora et al., 2015). The absorbance was read at $690 \mathrm{~nm}$ using a Synergy HT multi-well plate reader (BioTek, Winooski, VT, USA) and the results were expressed as $\mathrm{mg}$ gallic acid equivalents (GAE)/g of soluble fraction.

\subsection{Determination of individual phenolic compounds}

Phenolics extraction from lentil samples was performed according to a previously described method (Dueñas, Martínez-Villaluenga, Limón, Peñas, \& Frias, 2015). Briefly, lentil soluble fractions (2 g) were macerated in methanol:water:trifluoroacetic acid (80:19.9:0.1, v/v/v) at $4{ }^{\circ} \mathrm{C}$ for $16 \mathrm{~h}$. Subsequently, they were centrifuged at $4000 \times g$ and $5^{\circ} \mathrm{C}$ for $20 \mathrm{~min}$ in a Sorval RC 5B super-speed centrifuge (GMI, San Diego, CA, USA). The extracts were concentrated at $30^{\circ} \mathrm{C}$ under vacuum for methanol evaporation. For phenolic analysis, the dry extracts were dissolved in $10 \mathrm{~mL}$ of water. For purification, an aliquot $(4 \mathrm{~mL})$ was passed through a C18 Sep-Pak cartridge (Waters, Milford, MA, USA), previously activated with $2 \mathrm{~mL}$ of methanol followed by $3 \mathrm{~mL}$ of 
distilled water.

Samples were analyzed using Hewlett-Packard 1100MS (Agilent Technologies, Palo Alto, CA, USA) chromatograph coupled to an HP Chem Station (rev.A.0504) data-processing software. Double online detection was carried out in the DAD using $280 \mathrm{~nm}$ and $370 \mathrm{~nm}$ as preferred wavelengths. Mass spectrometer connected to the high-performance liquid chromatography system via the diode array detector cell outlet was used and detection was performed in an API 3200 Qtrap (Applied Biosystems, Darmstadt, Germany) equipped with an electrospray ionization source, triple quadrupole-ion trap mass analyzer and controlled by the Analyst 5.1 software, following the method described by Dueñas et al. (2015).

Phenolic compounds were characterized according to their UV and mass spectra, retention time, and comparison with authentic standards when available. For quantitative analysis, calibration curves were prepared by injection of known concentrations of different standard compounds. The standards, vanillic, trans-p-coumaric acids, (+)-catechin, isorhamnetin 3-O-glucoside and kaempferol 3-O-rutinoside were obtained from Extrasynthese (Genay Cedex, France). Concentration of hexosides and quinic derivatives of vanillic, hydroxybenzoic and $p$ coumaric acids were calculated by external calibration curves of their corresponding free acids while concentration of derivatives of isorhamnetin, kaempferol and $(+)$-catechin were calculated by external calibration of isorhamnetin 3-O-glucoside, kaempferol 3-O-glucoside and $(+)$-catechin and prodelphinidin dimer. All samples were analyzed in duplicate. Data were expressed as $\mu \mathrm{g} / \mathrm{g}$ of soluble fraction.

\subsection{Identification of peptides and prediction of their biological activity potential}

The proteomic analysis was performed by ultra performance liquid chromatography coupled to mass spectrometry analysis as previously described (Garcia-Mora et al., 2017). Briefly, the most active fraction collected by size exclusion chromatography was purified using a C18 ZipTip reverse phase column (Millipore, Darmstadt, Germany) and injected in the linear trap quadrupole Orbitrap Velos (Fisher Scientific, Madrid, Spain). Peptides separated in a AcclaimPepMap C18 column (inner diameter $75 \mu \mathrm{m}, 15 \mathrm{~cm}$ long, $3 \mu \mathrm{m}$ particle size) (Fisher Scientific, Madrid, Spain) and eluted using a solvent gradient at a flow rate of $250 \mathrm{~nL} / \mathrm{min}$ on a nanoEasy ultra-performance liquid chromatography coupled to a nanoelectrospray ion source (Fisher Scientific, Madrid, Spain). The mobile phases used consisted of $0.1 \%$ formic acid $/ 2 \%$ acetonitrile in water (solvent A) and $0.1 \%$ formic acid in acetonitrile (solvent B).

Proteome Discoverer 1.4.1.14 (Fisher Scientific, Madrid, Spain) with MASCOT 2.3 was used to search the Lens culinaris database (NCBI 427 sequences). Database search parameters used were the following: the cysteine carbamidomethylation and methionine oxidation were established as fixed modifications; precursor ion tolerance, $10 \mathrm{ppm}$; fragment ion tolerance, 0.5 Da. Peptides identification was validated through Percolator's algorithm using q-value $\leq 0.01$.

\subsection{ACE inhibitory activity}

Lentil samples $(0.3 \mathrm{mg} / \mathrm{mL}$ final concentration) were tested for ACE inhibitory activity following a previously described method (GarciaMora et al., 2014). Fluorescence was read every minute for $30 \mathrm{~min}$ at emission and excitation wavelengths of 335 and $405 \mathrm{~nm}$, respectively, in a microplate reader Synergy HT (BioTek, Winooski, VT, USA). The results were expressed as percent inhibition relative to the negative control having $100 \%$ enzymatic activity. All samples were analyzed in duplicate. $\mathrm{IC}_{50}$ values (concentration of sample in $\mathrm{mg} / \mathrm{mL}$ that inhibits $50 \%$ of the ACE activity) were calculated plotting the non-linear regression sigmoidal dose-response curves in GraphPad Prism 4.00 (GraphPad Software Inc., San Diego, CA, USA).

\section{9. $\alpha$-Glucosidase inhibitory activity}

Lentil samples $(1.7 \mathrm{mg} / \mathrm{mL}$ final concentration) were tested for $\alpha$ glucosidase inhibitory activity following a previously described method (Vilcacundo, Martinez-Villaluenga, \& Hernández-Ledesma, 2017). Glucose concentration in the reaction mixtures was determined using the Amplex ${ }^{\circledast}$ Red glucose/glucose oxidase assay kit (Invitrogen, Carlsbad, CA, USA). Absorbance was measured using a Synergy HT plate reader (BioTek, Winooski, VT, USA) at $560 \mathrm{~nm}$. Glucose concentration was calculated using a linear standard curve $(0-200 \mu \mathrm{M})$ from a freshly prepared $400 \mathrm{mM}$ stock solution. All samples were analyzed in duplicate. Percent inhibition of sucrase and maltase activity of intestinal $\alpha$-glucosidase in the presence of lentil samples was calculated relative to the negative control having $100 \%$ enzyme activity.

\subsection{Lipase inhibitory activity}

The ability of the fractions to inhibit porcine pancreatic lipase was evaluated using a previously reported method (Kim et al., 2010). Lipase activity was determined by measuring the hydrolysis of $p$-nitrophenyl butyrate to $p$-nitrophenol at $405 \mathrm{~nm}$ using a microplate reader Synergy HT (BioTek, Winooski, VT, USA). All samples were analyzed in duplicate. Percent inhibition of lipase activity in the presence of lentil samples was calculated relative to the negative control having $100 \%$ enzyme activity.

\subsection{Oxygen radical absorbance capacity}

Radical scavenging activity of lentil samples was evaluated by fluorescence following the oxygen radical absorbance capacity (ORAC) assay described previously (Garcia-Mora et al., 2017). Briefly, fresh soluble fractions from all lentil samples were obtained after treatment by centrifugation at $7500 \times g$ at $5^{\circ} \mathrm{C}$ for $15 \mathrm{~min}$. Supernatants were stabilized by heating at $70^{\circ} \mathrm{C}$ during $10 \mathrm{~min}$ for enzymatic inactivation. Samples were tested using different dilution factors (50, 100 and 200). Fluorescence was measured in a Synergy HT microplate reader (BioTek, Winooski, VT, USA) at emission and excitation wavelengths of $520 \mathrm{~nm}$ and $485 \mathrm{~nm}$, respectively. A Trolox standard curve with a linear concentration range $(0-160 \mu \mathrm{M})$ was prepared from a freshly made $1 \mathrm{mM}$ stock solution. All samples were analyzed in duplicate. Results were expressed as $\mathrm{mM}$ of Trolox equivalents (TE)/g of soluble fraction.

\subsection{Protective effect on intracellular ROS generation}

Murine macrophage cell line RAW 264.7 (American Type Culture Collection, Rockville, MD, USA) were maintained in Dulbecco's modified Eagles's medium (Lonza, Madrid, Spain) supplemented with 10\% fetal bovine serum (Lonza, Madrid, Spain) and 1\% penicillin/streptomycin $(5000 \mathrm{U} / \mathrm{mL})$ (Lonza, Madrid, Spain) at $37^{\circ} \mathrm{C}$ in a humidified incubator containing $5 \% \mathrm{CO}_{2}$ and $95 \%$ air. Cell viability was determined using Cell titer 96 Aqueous One Solution assay kit (Promega, Madison, WI, USA). A non-toxic and realistic physiological dose of $100 \mu \mathrm{g} / \mathrm{mL}$ (Supplemental Fig. S1) was used to examine the potential protective effect of lentil samples. Intracellular ROS were quantified by the dichlorofluorescein assay as previously described (Martin, CorderoHerrera, Bravo, Ramos \& Goya, 2014). Macrophages (2x10 5 cells/well) were pre-treated with lentil samples $(0.1 \mathrm{mg} / \mathrm{mL}$ final concentration) dissolved in serum-free medium for $20 \mathrm{~h}$. Cells were washed with phosphate buffer saline (PBS) and incubated with $20 \mu \mathrm{M}$ 2,7-dichlorofluorescin diacetate (Sigma-Aldrich, Madrid, Spain) for $30 \mathrm{~min}$. After that, cells were washed with PBS and treated with serum-free medium containing $2.5 \mathrm{mM}$ tert-butyl hydroperoxide ( $t$ - $\mathrm{BOOH}$ ) (Sigma-Aldrich, Madrid, Spain). ROS production was monitored for $3 \mathrm{~h}$ by fluorescence at an excitation and emission wavelengths of $485 \mathrm{~nm}$ and $530 \mathrm{~nm}$, respectively using a Synergy HT plate reader (BioTek, Winooski, VT, USA). Control cells with and without $t-\mathrm{BOOH}$ treatment were used as 
Table 1

Peptides, individual and total phenolic compounds of bioaccessible (soluble) fraction from control and bioprocessed lentil flour (HS, FLP, FLPS).

\begin{tabular}{|c|c|c|c|c|}
\hline Compounds & Control & HS & FLP & FLPS \\
\hline Peptides (mg/g) & $63.06 \pm 2.81^{\mathrm{a}}$ & $230.60 \pm 8.02^{c}$ & $99.62 \pm 4.10^{\mathrm{b}}$ & $229.99 \pm 8.06^{c}$ \\
\hline \multicolumn{5}{|l|}{ Individual phenolic compounds } \\
\hline Dimer prodelphinidin $(\mathrm{GC}-\mathrm{C})(\mu \mathrm{g} / \mathrm{g})$ & $111.70 \pm 10.53^{\mathrm{b}}$ & $14.13 \pm 0.59^{\mathrm{a}}$ & $16.23 \pm 0.17^{\mathrm{a}}$ & $10.85 \pm 2.70^{\mathrm{a}}$ \\
\hline$(+)$-catechin-3-O-glucoside $(\mu \mathrm{g} / \mathrm{g})$ & $267.33 \pm 3.98^{c}$ & $62.71 \pm 5.13^{b}$ & $12.55 \pm 1.93^{\mathrm{a}}$ & $16.11 \pm 0.80^{\mathrm{a}}$ \\
\hline trans-p-coumaric acid derivative $(\mu \mathrm{g} / \mathrm{g})$ & $24.23 \pm 0.27^{c}$ & $\mathrm{nd}^{\mathrm{a}}$ & $2.23 \pm 0.16^{\mathrm{b}}$ & $3.35 \pm 1.23^{\mathrm{b}}$ \\
\hline$(+)$-catechin $(\mu \mathrm{g} / \mathrm{g})$ & $41.10 \pm 3.25^{c}$ & $8.79 \pm 0.22^{\mathrm{a}}$ & $12.61 \pm 1.37^{\mathrm{b}}$ & $17.96 \pm 1.85^{\mathrm{b}}$ \\
\hline trans-p-coumaroyl malic acid $(\mu \mathrm{g} / \mathrm{g})$ & $14.18 \pm 0.56^{\mathrm{c}}$ & $\mathrm{nd}^{\mathrm{a}}$ & $14.37 \pm 0.99^{c}$ & $11.93 \pm 1.32^{\mathrm{b}}$ \\
\hline$p$-hydroxybenzoic acid $(\mu \mathrm{g} / \mathrm{g})$ & $7.71 \pm 0.86^{\mathrm{b}}$ & $\mathrm{nd}^{\mathrm{a}}$ & $22.29 \pm 0.43^{\mathrm{c}}$ & $48.40 \pm 1.01^{\mathrm{d}}$ \\
\hline trans-p-coumaroyl glycolic acid $(\mu \mathrm{g} / \mathrm{g})$ & $25.71 \pm 2.88^{\mathrm{d}}$ & $\mathrm{nd}^{\mathrm{a}}$ & $8.27 \pm 1.09^{\mathrm{b}}$ & $14.82 \pm 1.15^{\mathrm{c}}$ \\
\hline Vanillic acid $(\mu \mathrm{g} / \mathrm{g})$ & $2.66 \pm 0.73^{\mathrm{b}}$ & $\mathrm{nd}^{\mathrm{a}}$ & $14.91 \pm 0.63^{c}$ & $16.17 \pm 1.52^{\mathrm{d}}$ \\
\hline Kaempferol dirutinoside $(\mu \mathrm{g} / \mathrm{g})$ & $631.29 \pm 38.14^{\mathrm{b}}$ & $328.99 \pm 8.42^{\mathrm{a}}$ & $677.91 \pm 21.62^{\mathrm{c}}$ & $609.39 \pm 52.85^{\mathrm{b}}$ \\
\hline Kaempferol rutinoside-hexoside $(\mu \mathrm{g} / \mathrm{g})$ & $62.04 \pm 1.24^{\mathrm{c}}$ & $19.33 \pm 0.84^{\mathrm{a}}$ & $45.81 \pm 1.81^{\mathrm{b}}$ & $45.04 \pm 1.45^{\mathrm{b}}$ \\
\hline Isorhamnetin glucuronide $(\mu \mathrm{g} / \mathrm{g})$ & $30.90 \pm 4.14^{\mathrm{a}}$ & $27.13 \pm 0.96^{\mathrm{a}}$ & $43.78 \pm 0.40^{\mathrm{b}}$ & $30.90 \pm 4.29^{\mathrm{a}}$ \\
\hline trans-p-coumaric acid $(\mu \mathrm{g} / \mathrm{g})$ & $41.61 \pm 1.43^{\mathrm{c}}$ & $\mathrm{nd}^{\mathrm{a}}$ & $2.99 \pm 0.31^{\mathrm{b}}$ & $4.17 \pm 1.15^{\mathrm{b}}$ \\
\hline Kaempferol rutinoside-rhamnoside (I) $(\mu \mathrm{g} / \mathrm{g})$ & $42.11 \pm 0.29^{d}$ & $1.55 \pm 0.35^{\mathrm{a}}$ & $23.78 \pm 1.21^{\mathrm{b}}$ & $26.39 \pm 0.69^{c}$ \\
\hline Kaempferol rutinoside-rhamnoside (II) $(\mu \mathrm{g} / \mathrm{g})$ & $8.65 \pm 1.19^{\mathrm{b}}$ & $3.52 \pm 0.58^{\mathrm{a}}$ & $14.44 \pm 0.77^{\mathrm{c}}$ & $13.93 \pm 2.61^{\mathrm{c}}$ \\
\hline Kaempferol $(\mu \mathrm{g} / \mathrm{g})$ & $8.90 \pm 1.49^{c}$ & $\mathrm{nd}^{\mathrm{a}}$ & $2.81 \pm 0.10^{\mathrm{b}}$ & $10.54 \pm 2.18^{\mathrm{c}}$ \\
\hline Total identified phenolics $(\mu \mathrm{g} / \mathrm{g})$ & $1320.12 \pm 170.35^{\mathrm{c}}$ & $466.15 \pm 21.20^{\mathrm{a}}$ & $914.96 \pm 24.21^{\mathrm{b}}$ & $879.93 \pm 60.49^{b}$ \\
\hline
\end{tabular}

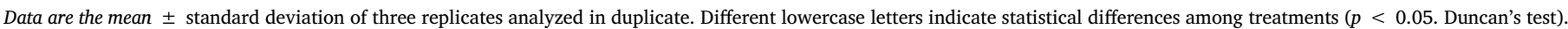

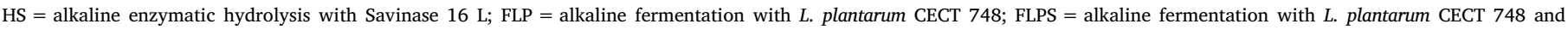
enzymatic hydrolysis with Savinase 16 L; GC-C: gallocatechin-catechin; nd: not detected.

positive and negative controls, respectively. All samples were analyzed in duplicate. The results were expressed as percentage inhibition of ROS generation relative to $t$-BOOH-stressed cells.

\subsection{Statistical analysis}

Experimental data represent the mean and standard deviation of three replicates analyzed in duplicate. Statistical significance of the data was tested by one-way analysis of variance, followed by the Duncan test to compare the means that showed significant variation ( $\mathrm{p}<0.05$ ); all of the statistical analyses were performed using Statgraphics Plus software, version 5.1 (Statistical Graphics Corporation, Rockville, MD, USA).

\section{Results and discussion}

\subsection{Effect of processing on peptide, total and individual phenolic concentration of lentil bioaccessible (soluble) fraction}

As compared among treatments, HS and FLPS soluble fractions showed significantly higher peptide concentrations than FLP (Table 1), which indicates that generation of peptides in FLPS is mainly attributed to Savinase protease activity. Our results are consistent with previous studies showing Savinase as one of the most efficient commercial enzymes to hydrolyze lentil proteins (Garcia-Mora et al., 2014). L. plantarum CECT 748 was also able to release peptides from lentil proteins at alkaline $\mathrm{pH}$ although in a lesser extent than Savinase. In consistency with our results, recent studies have demonstrated that L. plantarum strains are able to release peptides from different legume protein sources (Singh \& Vij, 2017; Jakubczyk, Karas, Zlotek, \& Szymanowska, 2017). L. plantarum genome does not encode the extracellular protease Prt that is involved in primary breakdown of proteins (Kleerebezem et al., 2003). However, it has uptake systems for peptides (Opp and Dtp) and produces intracellular peptidases of different specificity. Therefore, generation of peptides in FLP could has been caused by the action of $L$. plantarum CECT 748 peptidases.

Prior to lentil treatment, Hydroxycinnamic and hydroxybenzoic acids were found as minor soluble phenolic compounds in lentil (8\% and $1 \%$ of total soluble phenolics, respectively) while flavonoids were the most prominent phenolic group (Table 1). Flavonols (kaempferol aglycone and glucosides as well as isorhamnetin glucuronide) accounted for $76 \%$ of the total soluble phenolics, being kaempferol dirutinoside the most abundant compound. (+ )-Catechin-3-O-glucoside was the main flavan-3-ol found in the soluble fraction followed by prodelphinidin dimer and (+)-catechin. Phenolic composition of nonprocessed lentil was consistent with the phenolic profiles of the lentil flour (Supplemental Table S1) and previous reported results for 20 Canadian lentil cultivars in which flavonoid glycosides, mainly kaempferol glycosides, are the major extractable phenolics of lentils and in much lower amounts $p$-coumaric and $p$-hydroxybenzoic acids (Zhang et al., 2015). Sum of concentrations of all phenolic compounds detected in control lentil was $1320.12 \mu \mathrm{g} / \mathrm{g}$ of soluble fraction.

After lentil processing, significant qualitative and quantitative differences were observed in the total and individual phenolic content of lentil soluble fraction (Table 1). It was observed that the sum of all identified phenolic compounds was significantly lower in HS and FLP compared to control $(p<0.05)$. Hydroxycinnamic and hydroxybenzoic acids became undetectable in HS that was composed mainly by flavonols and flavan-3-ols. This finding does not agree with our recent study where we have shown that the combined action of protease and esterase activities of Savinase increased the bioaccessibility of phenolic compounds that were bound to polysaccharides and proteins in pinto bean (Garcia-Mora et al., 2015). This could be explained by lower time of hydrolysis ( $5 \mathrm{~h}$ vs $15 \mathrm{~h}$ used in the present work), and hence, lower phenolic compounds degradation in alkaline conditions. For instance, the stability of catechins is $\mathrm{pH}$-dependent; they are very unstable in alkaline solutions diminishing their content by $70-80 \%$ at pH 7.4 within 60 min (Hur, Lee, Kim, Choi, \& Kim, 2014). Similarly, lentil fermentation in alkaline conditions generally decreased individual phenolic concentrations, although for certain compounds similar or increased concentrations were observed. In particular, fermentation did not affect $p$-coumaroyl malic acid concentration; however, significantly higher concentrations of $p$-hydroxybenzoic and vanillic acids, isorhamnetin glucuronide and kaempferol dirutinoside were found in FLP $(p<0.05)$. Microbial metabolism of $L$. plantarum CECT 748 was responsible for the changes observed in the phenolic profiles of lentil soluble fraction. L. plantarum produces carbohydrolases, $\beta$-glucosidases and a wide range of esterases which are highly specific and effective in releasing bound phenolic compounds that are cross-linked to plant cell wall matrix (Esteban-Torres, Reverón, Santamaría, de las Rivas, \& Muñoz, 2015). Therefore, the increased bioaccessibility of $p$-hydroxybenzoic and vanillic acids, isorhamnetin glucuronide and kaempferol dirutinoside in FLP could be due to microbial enzymatic activities. Free p-coumaric acids may be 
decarboxylated or reduced by $L$. plantarum phenolic acid decarboxylases or reductases to the corresponding phenol or vinyl derivatives (Filannino, Di Cagno, \& Gobbetti, 2018). Therefore, these microbial metabolic pathways could explain the reduction of soluble $p$-hydroxycinnamic compounds in FLP. On the other hand, microbial metabolism along with alkaline-induced degradation could explain the lower content of some flavonoid compounds such as $(+)$-catechin and (+)-catechin-3-O-glucoside (Hur et al., 2014).

Sum of concentrations of all phenolic compounds identified in FLPS $(879.93 \mu \mathrm{g} / \mathrm{g}$ ) was lower than in control. Combined enzymatic hydrolysis and fermentation reduced individual concentration of some phenolic compounds $(p<0.05)$. Conversely, $p$-hydroxybenzoic acid, vanillic acid and kaempferol rutinoside-rhamnoside II concentrations significantly increased $(p<0.05)$. On the other hand, there were no significant differences in kaempferol dirutinoside, isorhamnetine glucuronide and kaempferol concentrations in the soluble fraction of FLPS compared to control $(p>0.05)$. As explained above, phenolic composition of FLPS may be attributed to L. plantarum CECT 784 metabolism, protease and esterase activities of Savinase as well as alkalineinduced degradation (Hur et al., 2014; Garcia-Mora et al., 2015; Filannino et al., 2018). As compared among treatments, individual phenolics concentrations of FLPS were closer to FLP and sums of concentrations of all identified compounds were not significantly different ( $p>0.05$ ). Therefore, we may assume that $L$. plantarum metabolism was the main contributor to the phenolic profiles of FPLS.

\subsection{Effect of processing on biological activity of lentil bioaccesible (soluble) fraction}

This research objectively evaluated whether combined fermentation and enzymatic hydrolysis enhance the potential health benefits of lentil bioaccessible fraction. Moreover, results in Table 2 facilitate examination of the individual effects of HS and FLP on enzyme inhibition abilities (ACE, $\alpha$-glucosidase and lipase inhibitory) and antioxidant activity of lentil soluble fraction. In order to elucidate the mechanisms by which changes in the biological activities of lentil soluble fraction have occurred, comparisons of FLPS to HS and FLP were performed and attributed to peptide content and phenolic profiles.

ACE inhibition through dietary compounds has been proven as an efficient strategy to reduce blood pressure in vivo, which constitutes a key point to prevent or delay the cardiovascular disease risk of hypertension (Lee \& Hur, 2017). ACE inhibitory activity of bioaccessible fraction at $0.5 \mathrm{mg} / \mathrm{mL}$ was improved in HS, FLP and FLPS from undetectable (in control sample) to $61.5-85.3 \%$ inhibition $(p<0.05)$. FLPS showed the lowest $\mathrm{IC}_{50}$ value $\left(\mathrm{IC}_{50}=0.14 \mathrm{mg} / \mathrm{mL}\right.$ ), followed by
HS ( $\left.\mathrm{IC}_{50}=0.18 \mathrm{mg} / \mathrm{mL}\right)$ and FLP ( $\left.\mathrm{IC}_{50}=0.29 \mathrm{mg} / \mathrm{mL}\right)$, suggesting that combination of fermentation and enzymatic hydrolysis enhanced inhibition of ACE. Moreover, ACE inhibitory activity of FLPS was found higher than reported values for legumes fermented with $L$. plantarum strains $\left(\mathrm{IC}_{50}=0.19-0.53 \mathrm{mg} / \mathrm{mL}\right.$ ) (Singh \& Vij, 2017; Jakubczyk et al., 2017; Torino et al., 2013) and within the range $\left(\mathrm{IC}_{50}=0.08-0.3 \mathrm{mg} /\right.$ $\mathrm{mL}$ ) of reported values for lentil hydrolysates produced by commercial proteases (Garcia-Mora et al., 2014). As compared by the IC $_{50}$ values of the different lentil treatments, it may be indicated that Savinase was the main contributor to the ACE inhibitory activity of FLPS. Our earlier studies have demonstrated the suitability of Savinase compared to other commercial enzymes to produce lentil hydrolysates with a high yield of ACE inhibitory peptides (Garcia-Mora et al., 2014). This higher efficiency of Savinase to generate ACE inhibitory peptides has been attributed to its specificity for aromatic and hydrophobic residues at position P1 (Garcia-Mora et al., 2017). As determined by the IC $_{50}$ value of FLP, L. plantarum could also be contributing to the ACE inhibitory activity of FLPS through generation of ACE inhibitory peptides as reported previously in fermented legumes (Torino et al., 2013; Singh \& Vij, 2017; Jakubczyk et al., 2017). Phenolic acids and flavonoids have proven to inhibit ACE activity in vitro, although this biological effect has been shown at supra-physiological concentrations (IC $_{50}$ ranging from 0.23 to $9.30 \mathrm{mM}$ ) (Al Shukor et al., 2013). These results along with the absence of evidence in the literature of associations between ACE inhibitory activity of fermented foods and changes in the phenolic profiles, suggest that generation of peptides by L. plantarum and Savinase is the only mechanism for the improvement of ACE inhibitory activity observed in FLPS.

Small intestinal $\alpha$-glucosidases, maltase-glucoamylase (MGAM) and sucrase-isomaltase (SI), break down disaccharides and glucose oligomers, releasing glucose for the enterocyte uptake. These enzymes have two homologous functional units on the respective C- and N-terminal (Ct and Nt, respectively) of their original protein that differ in substrate specificity (Gericke, Schecker, Amiri, \& Naim, 2017). In MGAM, Ct has a higher specificity for glucose oligomers while Nt has been ascribed as the maltase subunit. Ct-SI and Nt-SI subunits display distinctive sucrase and isomaltase activities, respectively. It is a fact that the inhibition of the intestinal $\alpha$-glucosidases may have multiple positive health implications related to control of the glycemic response profile of starchy foods and perhaps eliciting the ileal break and gut-brain axis response to reduce appetite and food intake (Simsek et al., 2015). One achievement of our study is that inhibitory effect of lentil soluble fraction was investigated for both sucrase and maltase activities of intestinal rat $\alpha$-glucosidases unlike most previous works. This methodological approach was adequate to allow measurement of selective

Table 2

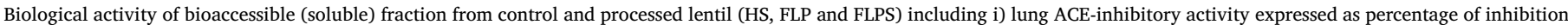

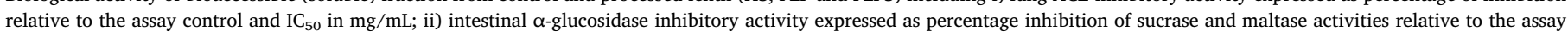

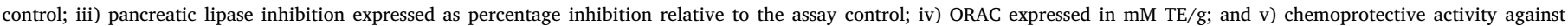
oxidative stress expressed as percentage reduction of ROS generation relative to $t$-BOOH-stressed RAW 264.7 macrophages.

\begin{tabular}{|c|c|c|c|c|}
\hline \multirow[t]{2}{*}{ Biological activity } & \multicolumn{4}{|l|}{ Lentil treatment } \\
\hline & Control & HS & FLP & FLPS \\
\hline ACE inhibition (\%) & nd & $76.54 \pm 0.94^{\mathrm{b}}$ & $61.48 \pm 5.89^{\mathrm{a}}$ & $85.35 \pm 2.36^{\mathrm{c}}$ \\
\hline $\begin{array}{l}\text { ACE inhibition }\left(\mathrm{IC}_{50}, \mathrm{mg} / \mathrm{mL}\right) \\
\alpha \text {-glucosidase inhibition }(\%)\end{array}$ & $1.10 \pm 0.26^{b}$ & $0.18 \pm 0.01^{\mathrm{a}, \S}$ & $0.29 \pm 0.02^{\mathrm{a}}$ & $0.14 \pm 0.01^{\mathrm{a}, *}$ \\
\hline Sucrase activity & $81.11 \pm 5.02^{\mathrm{d}}$ & $19.83 \pm 0.15^{\mathrm{a}}$ & $31.73 \pm 1.33^{\mathrm{b}}$ & $53.24 \pm 8.72^{c}$ \\
\hline Maltase activity & $29.99 \pm 1.40^{\mathrm{b}}$ & $37.82 \pm 2.10^{\mathrm{c}}$ & $22.09 \pm 2.86^{\mathrm{a}}$ & $38.06 \pm 0.17^{\mathrm{c}}$ \\
\hline Lipase inhibition (\%) & $90.46 \pm 6.50^{\mathrm{d}}$ & $9.96 \pm 4.98^{\mathrm{a}}$ & $44.46 \pm 0.64^{\mathrm{c}}$ & $39.67 \pm 3.64^{\mathrm{b}}$ \\
\hline ORAC (mM TE/g) & $302.69 \pm 25.58^{\mathrm{b}}$ & $384.46 \pm 22.70^{\mathrm{c}}$ & $260.11 \pm 23.60^{\mathrm{a}}$ & $508.78 \pm 48.14^{\mathrm{d}}$ \\
\hline Inhibition of ROS generation (\%) & $17.60 \pm 1.13^{\mathrm{a}}$ & $42.32 \pm 2.42^{\mathrm{bc}}$ & $49.53 \pm 4.56^{c}$ & $40.13 \pm 2.48^{b}$ \\
\hline
\end{tabular}

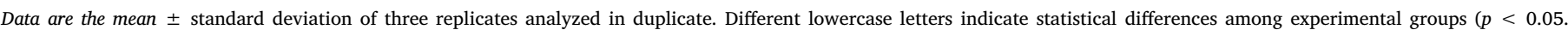

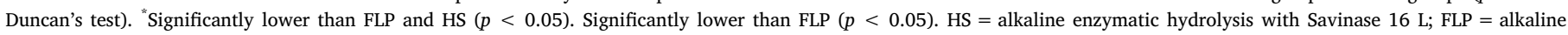

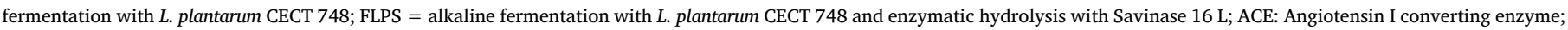
ORAC: oxygen radical absorbance capacity; ROS: radical oxygen species. nd: not detected. 
inhibition of individual $\alpha$-glucosidases. Lentil soluble fraction at $1 \mathrm{mg} /$ mL strongly inhibited sucrase (81.11\%) and maltase (29.99\%) activities (Table 2). Lentil phenolic compounds, especially kaempferol and quercetin glycosides, were described as good inhibitors of intestinal $\alpha$ glucosidases (Zhang et al., 2015). Interestingly, lentil soluble fraction inhibited more potently sucrase than maltase activity, which suggests a selective inhibition mode of lentil soluble fraction. Consistently with our findings, Simsek, Quezada-Calvillo, Feruzzi, Nichols, and Hamaker (2015) demonstrated that individual phenolic compounds are selective inhibitors of individual mucosal $\alpha$-glucosidase subunits. For instance, (+)-catechin, a phenolic compound detected in lentil soluble extracts, inhibited more potently SI than MGAM subunits which is consistent with our results (Simsek et al., 2015). Lentil treatment reduced significantly the sucrase inhibitory activity of the soluble fraction (Table 2, $p<0.05$ ). Significant losses of some phenolic compounds during HS, FLP and FLPS may explain the decrease in sucrase inhibitory activity of lentil soluble fractions. Conversely, HS and FLPS showed a higher inhibition of maltose digestion than control; however, in FLP maltase inhibitory activity was significantly reduced $(p<0.05)$. Among treatments, FLPS showed a better hypoglycemic potential through inhibition of digestion of both maltose and sucrose compared to HS and FLP. As compared by the percentages of inhibition, it seems that both Savinase and L. plantarum were contributors to the maltase inhibitory activity of FLPS while Savinase was mainly contributing to the sucrase inhibitory activity of FLPS. Taking into account that legume peptides have been described as inhibitors of $\alpha$-glucosidases (Mojica, Luna-Vital, \& de Mejia, 2017; Jakubczyk et al., 2017), and that Savinase contributed to the release of peptides rather than phenolics in the present study, we may assume that besides phenolics, peptides could be also responsible for the $\alpha$-glucosidase inhibitory activity of FLPS. Although we have not studied further the FLPS process, these initial findings related to the selective inhibition of small intestine $\alpha$-glucosidases by lentil peptides and phenolics justify additional studies.

Inhibition of pancreatic lipase through dietary compounds has also been proposed to have a positive health impact to control hyperlipidaemia and weight gain through suppression and delay of triglyceride digestion and absorption (Finer, James, Kopelman, Lean, \& Williams, 2000). Lentil soluble fraction showed a potent pancreatic lipase inhibitory activity at $2 \mathrm{mg} / \mathrm{mL}\left(90.46 \%\right.$ inhibition, IC $_{50}<2 \mathrm{mg} / \mathrm{mL}$, Table 2). This effect was mainly attributed to phenolic compounds, being kaempferol glycosides and aglycones the most potent inhibitors followed by quercetin arabinoside and aglycone (Zhang et al., 2015). After lentil treatment, a significant loss of lipase inhibitory activity was observed in the soluble fraction $(p<0.05)$. In the present study, a correlation analysis indicated a strong positive association $(r=0.998$, $p<0.05$ ) between total content of kaempferol glycosides and aglycones and lipase inhibitory activity of lentil soluble fractions. This finding indicated that decrease of lipase inhibitory activity of lentil soluble fractions was likely due to degradation of kaempferols during bioprocessing. Lipase inhibitory activity decreased with lentil treatment as follows: HS > FLPS > FLP, suggesting that FLP preserve in a greater extent than Savinase the lipase inhibitory activity of lentil. In contrast with the results obtained for other bioactive compounds, our findings indicate that FPLS did not enhance the potential of lentil to control hyperlipidemia and weight gain through pancreatic lipase inhibition.

Oxidative stress has been involved in different pathologies, including metabolic syndrome and numerous cardiovascular diseases. The antioxidant and chemopreventive effects of lentil after bioprocessing was investigated by chemical (ORAC method) and cellular assays using the RAW 264.7 macrophage cell line. The ORAC values of lentil soluble fraction were within the range of previously reported values for different legumes (Zhang et al., 2015, Singh \& Vij, 2017). Phenolic compounds display antioxidant activity although low correlations previously found between ORAC values and total phenolic compounds and flavonoid content indicate that these compounds are not the only antioxidants in lentil (Zhang et al., 2015). FLPS was shown to be approximately two times more effective for increasing the peroxyl scavenging activity of lentil soluble fraction than HS and FLP $(p<0.05)$, therefore, combination of both bioprocesses may synergically generate antioxidant compounds acting as radical scavengers through hydrogen donating mechanisms. We have observed that HS increased significantly ORAC values of lentil soluble fraction as opposed to FLP that showed a lower antioxidant activity compared to control $(p<0.05)$. These results indicated that Savinase could be contributing in a greater extent to the antioxidant activity of FLPS. Savinase hydrolysis has previously shown to enhance ORAC values of lentil due to generation of small peptides able to donate hydrogen atoms (Garcia-Mora et al., 2014; 2015). Similarly, FLP has demonstrated to enhance ORAC in different legumes due to bioconversion of native phenolics (Torino et al., 2013; Limon et al., 2015).

To test the cytoprotective effect of lentil soluble fractions in stressful conditions, a model of oxidative stress induced by a potent pro-oxidant was established based on previous studies (Lv et al., 2017). $t$-BOOH can induce cell damage, mainly by overproduction of ROS, inhibiting cell viability and inducing cell apoptosis. Before starting the study, different $t$-BOOH concentrations were tested to assure that toxicity by oxidative stress on RAW 264.7 macrophages was produced. Results show that concentrations over $2.5 \mathrm{mM}$ evoke significant cell damage and over $50 \%$ cell death (Supplemental Fig. S2). Interestingly, cell pretreatment with lentil soluble fraction significantly reduced ROS overproduction induced by $t$ - $\mathrm{BOOH}(p<0.05)$. As with our results, Xuan et al. (2013) demonstrated that lentil extracts can attenuate Angiotensin II-induced cardiomyocytes hypertrophy via decreasing ROS levels. In this study, antioxidant effect of lentil extracts against angiotensin II-induced oxidative stress were attributed to phenolic compounds which provide parallel protection by ROS quenching and activation of cell antioxidant defense system. Our results indicated that all treatments were effective to enhance the protective effects of lentil against oxidative stress (Table 2). The highest chemopreventive potential was found in FLP nearly followed by HS and FLPS. Unlike ORAC data, it was not found a clear synergistic effect of Savinase and $L$. plantarum combination on inhibition of cellular oxidative stress. The effects of fermentation or enzymatic hydrolysis on the chemopreventive potential of lentil on a cellular model of oxidative stress has not been investigated so far. Although we observed significant losses in native phenolic compounds from hydrolysis and fermentation in alkaline conditions these compositional changes did not affect the chemopreventive potential of lentil against oxidative stress. These findings led us to believe that other as yet unidentified compounds contribute to the observed biological activity. Upon examining the literature it is possible that microbial metabolites, peptides, or new compounds formed by condensation and oxidation reactions occurring during enzymatic and/or fermentation could be responsible for the observed effects (Filannino et al., 2018; Hur et al., 2014).

\subsection{Bioactivity-guided selection of most active subfractions from FLPS}

To identify and characterize the bioactive compounds released during FLPS, fractionation of soluble fraction was performed to obtain five subfractions (F1-F5) that were screened for their total peptide and phenolic contents as well as their health-promoting potential (Table 3). Fractions showed different peptide and phenolic composition and bioactive profile. All the bioactivities tested were found in all fractions with the exception of F3, F4 and F5 in which lipase inhibitory activity was not detected. Comparing the bioactivity data, there were two main outstanding fractions: F1 and F5. Fraction F1, composed by 56\% peptides and 5\% phenolics, had the highest ACE and lipase inhibitory activities and antioxidant potential measured as inhibition of ROS generation in $t$-BOOH challenged RAW 264.7 macrophages. Moreover, F1 inhibited noticeably maltose digestion by intestinal $\alpha$-glucosidase and showed a high antioxidant value measured as ORAC. Fraction F5 made 
Table 3

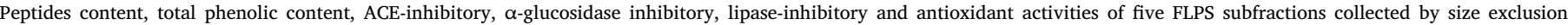
chromatography (F1-F5).

\begin{tabular}{|c|c|c|c|c|c|}
\hline & F1 & F2 & F3 & F4 & F5 \\
\hline Peptides (mg/g) & $560.26 \pm 27.20^{c}$ & $274.67 \pm 19.19^{\mathrm{b}}$ & $231.59 \pm 13.18^{\mathrm{a}}$ & $534.67 \pm 41.01^{\mathrm{c}}$ & $918.08 \pm 35.90^{d}$ \\
\hline Phenolics (mg GAE/g) & $50.48 \pm 1.71^{\mathrm{b}}$ & $36.77 \pm 2.47^{\mathrm{a}}$ & $61.15 \pm 2.00^{c}$ & $84.58 \pm 7.12^{\mathrm{d}}$ & $106.03 \pm 10.47^{\mathrm{e}}$ \\
\hline $\begin{array}{l}\text { ACE inhibition (\%) } \\
\alpha \text {-glucosidase inhibition (\%) }\end{array}$ & $88.21 \pm 6.78^{\mathrm{e}}$ & $30.81 \pm 2.27^{\mathrm{b}}$ & $23.34 \pm 2.41^{\mathrm{a}}$ & $44.88 \pm 2.87^{c}$ & $51.38 \pm 3.79^{d}$ \\
\hline Sucrase activity & nd & nd & $14.95 \pm 0.44^{\mathrm{a}}$ & $18.61 \pm 1.76^{\mathrm{a}}$ & $23.81 \pm 1.46^{\mathrm{b}}$ \\
\hline Maltase activity & $39.56 \pm 5.37^{\mathrm{a}}$ & $50.68 \pm 0.72^{\mathrm{b}}$ & $52.30 \pm 0.72^{\mathrm{b}}$ & $52.50 \pm 3.55^{\mathrm{b}}$ & $59.43 \pm 1.07^{\mathrm{c}}$ \\
\hline Lipase inhibition (\%) & $40.27 \pm 4.49^{\mathrm{a}}$ & $34.06 \pm 4.50^{\mathrm{a}}$ & nd & nd & nd \\
\hline ORAC (mM TE/g) & $497.77 \pm 24.97^{\mathrm{b}}$ & $305.70 \pm 6.99^{\mathrm{a}}$ & $338.19 \pm 13.69^{\mathrm{a}}$ & $528.45 \pm 43.07^{\mathrm{b}}$ & $592.67 \pm 46.06^{c}$ \\
\hline Inhibition of ROS generation (\%) & $45.36 \pm 1.74^{\mathrm{b}}$ & $46.69 \pm 2.60^{\mathrm{b}}$ & $22.68 \pm 4.98^{\mathrm{a}}$ & $39.43 \pm 4.98^{\mathrm{b}}$ & $26.33 \pm 1.95^{\mathrm{a}}$ \\
\hline
\end{tabular}

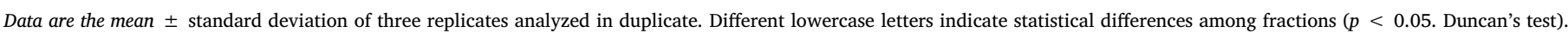

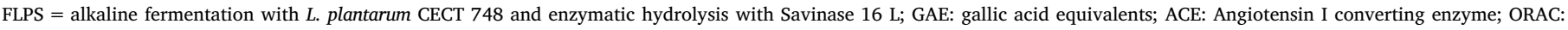
oxygen radical absorbance capacity; ROS: radical oxygen species; nd: not detected.

up of $91 \%$ peptides and $10 \%$ phenolics showed the highest $\alpha$-glucosidase inhibitory activity and ORAC. In contrast, F5 showed the weakest inhibition for ROS generation in $t$-BOOH-induced RAW 264.7 macrophages and inhibition of pancreatic lipase activity was not detected. Therefore, F1 was selected based on its multifunctional activity for characterization of bioactive peptides and phenolics.

\subsection{Composition of FPLS active fraction}

To gain insight into bioactive compounds contributing to multifunctional activity of FLPS, peptide and phenolic profiles of subfraction F1 were analyzed.

\subsubsection{Peptide profile}

Most abundant peptides in subfraction F1 are presented in Table 4. A total of 30 fragments with molecular masses within the range of 1100 to $3200 \mathrm{Da}$ were identified. These peptides derived from the major lentil proteins: convicilin, vicilin (allergen Len c 1.0101 and 1.0102) and lectin. Some peptides showed a good potential as ACE-inhibitory and antioxidant peptides. We identified three previously reported peptides (DLAIPVNNPGQLESF, LVNEGKGNLELVGF and EITPEKNPQLQDLDIF) with dual antioxidant and ACE-inhibitory activities (GarciaMora et al., 2017). Upon examination of amino acid sequences, many of the lentil peptides in Table 4 contained aromatic (phenylalanine), hydrophobic (valine, leucine, glycine, proline, phenylalanine) and positively charged amino acids (arginine and histidine) in the Ct-tripeptide which has been described as determinant residues for ACE inhibitory activity. Moreover, amino acid sequences containing proline, histidine or tyrosine within the sequence and $\mathrm{Nt}$ and/or Ct hydrophobic amino acids are determinant for antioxidant activity (Li \& Li, 2013). These structural features were found in most of the peptides collected in Table 4. Antioxidant activity of histidine residues is due to hydrogendonating and radical-trapping mechanisms, tyrosine residues can donate hydrogen to reduce free radicals and hydrophobic amino acids may increase interaction between peptides and fatty acids radicals (Li \& $\mathrm{Li}, 2013)$. Legume derived peptides are emerging as promising $\alpha$ -

Table 4

Most abundant peptides identified in subfraction F1 collected by size exclusion chromatography of lentil bioaccessible (soluble) fraction from FLPS

\begin{tabular}{|c|c|c|c|}
\hline Protein accessions & Sequence & Parent proteins & $\mathrm{MH}+(\mathrm{Da})$ \\
\hline 7688242 & SGREKWERKEDEEKVVEEEEGEWRGS & Convicilin & 3192.47 \\
\hline 29539109 & FNTEYEEIEKVLLEEQ & Allergen Len c 1.0101 & 2012.96 \\
\hline 29539109 & FNTEYEEIEKVLL & Allergen Len c 1.0101 & 1626.82 \\
\hline 29539109 & FNTEYEEIEKVLLEEQEQKSQ & Allergen Len c 1.0101 & 2613.25 \\
\hline 29539111 & FNTDYEEIEKVLL & Allergen Len c 1.0102 & 1612.80 \\
\hline 29539109 & FNTEYEEIEKVLLE & Allergen Len c 1.0101 & 1755.86 \\
\hline 29539109 & NTEYEEIEKVLL & Allergen Len c 1.0101 & 1479.75 \\
\hline 29539111 & NTDYEEIEKVLL & Allergen Len c 1.0102 & 1465.74 \\
\hline $26800840 ; 62910855 ; 7428789$ & KDVVPEWVRIGFS & Lectin, Lectin precursor & 1531.82 \\
\hline $29539109 ; 29539111$ & NLERGDTIKLPA & Allergen Len c 1.0101 and c 1.0102 & 1326.74 \\
\hline 29539111 & FNTDYEEIEKVLLEDQEQEPQHR & Allergen Len c 1.0102 & 2889.34 \\
\hline 7688242 & LNTKYDTIEKVLLEEQENEPH & Convicilin & 2542.26 \\
\hline 29539111 & DLAIPVNNPGQLESF & Allergen Len c 1.0102 & 1613.81 \\
\hline 7688242 & LVNPDDEEDLRVVDF & Convicilin & 1774.84 \\
\hline 7688242 & SLNTKYDTIEKVLLEEQENEPH & Convicilin & 2629.29 \\
\hline 29539109; 29539111 & YEEIEKVLL & Allergen Len c 1.0101 and c 1.0102 & 1135.62 \\
\hline 29539111 & FNTDYEEIEKVLLEDQEQEPQHRR & Allergen Len c 1.0102 & 3045.44 \\
\hline 29539109 & FNTEYEEIEKVL & Allergen Len c 1.0101 & 1513.74 \\
\hline 7688242 & TKYDTIEKVLLEEQENEPH & Convicilin & 2315.13 \\
\hline 29539111 & FNTDYEEIEKVLLEDQEQEPQHRRS & Allergen Len c 1.0102 & 3132.47 \\
\hline 29539109 & FNTEYEEIEKVLLEEQEQKSQH & Allergen Len c 1.0101 & 2750.31 \\
\hline 29539109;29539111 & EITPEKNPQLQDLDIF & Allergen Len c 1.0101 and c 1.0102 & 1899.96 \\
\hline 7688242 & LVNEGKGNLELVGF & Convicilin & 1488.80 \\
\hline $26800840 ; 62910855 ; 7428789$ & KDVVPEWVRIGFSA & Lectin, Lectin precursor & 1602.86 \\
\hline $164512514 ; 7688242$ & REQSPGQWRPSHGKEEDEEEKEQKEAQ & Convicilin & 3251.49 \\
\hline 29539109 & NTEYEEIEKVLLEEQEQKSQ & Allergen Len c 1.0101 & 2466.17 \\
\hline 29539109 & FNTEYEEIEKVLLEEQEQK & Allergen Len c 1.0101 & 2398.16 \\
\hline $164512514 ; 7688242$ & EDEEKVVEEEEGEWRGS & Convicilin & 2035.87 \\
\hline $29539109 ; 29539111$ & KFGKFFEITPEKNPQLQ & Allergen Len c 1.0101 and c 1.0102 & 2051.09 \\
\hline $26800840 ; 62910855 ; 7428789$ & KDVVPEWVRIGF & Lectin, Lectin precursor & 1444.79 \\
\hline
\end{tabular}


Table 5

Phenolic compounds identified in fraction F1 collected by size exclusion chromatography of lentil bioaccessible (soluble) fraction from FLPS.

\begin{tabular}{ll}
\hline Compounds & Concentration $(\mu \mathrm{g} / \mathrm{g})$ \\
\hline Dimer prodelphinidin (GC-C) & $0.33 \pm 0.11$ \\
(+)-catechin-3-O-hexoside & $0.25 \pm 0.10$ \\
Kaempferol rutinoside-hexoside & $1.00 \pm 0.45$ \\
Isorhamnetin glucuronide & $0.14 \pm 0.03$ \\
Kaempferol rutinoside-rhamnoside (II) & $\mathrm{t}$ \\
\hline
\end{tabular}

Data are the mean \pm standard deviation analyzed in triplicate. t: traces.

FLPS $=$ alkaline fermentation with $L$. plantarum CECT 748 and enzymatic hydrolysis with Savinase 16 L; GC-C: gallocatechin-catechin; t: traces.

glucosidase inhibitors for the treatment of type 2 diabetes (Mojica, Luna-Vital, \& González de Mejía, 2017). Typical structural features of food-derived peptides for high $\alpha$-glucosidase inhibitory activity consist of the presence of amino acids containing a hydroxyl or basic side chain at the $\mathrm{N}$-terminal (serine, threonine and tyrosine), proline within the chain and alanine or methionine at the C-terminal (Ibrahim, Bester, Neitz, \& Gaspar, 2017). All these residues at positions relevant for high inhibitory activity were found in peptide REQSPGQWRPSHGKEEDEEEKEQKEAQ derived from convicilin.

\subsubsection{Phenolic compounds}

Phenolic profiles and individual phenolic concentrations of subfraction F1 are shown in Supplemental Fig. S3 and Table 5, respectively. Five flavonoids were identified: prodelphinidin dimer, (+)-catechin-3-O-hexoside, kaempferol rutinoside-hexoside, isorhamnetin glucoronide and kaempferol rutinoside-rhamnoside (II). The kaempferol rutinoside-hexoside was the most abundant compound $(1 \mu \mathrm{g} / \mathrm{g})$ accounting for $58 \%$ of the total phenolics of F1. Flavonoids are well known antioxidants that may exert their action through several mechanisms. Earlier studies have shown that lentil flavonoids are able to neutralize radicals and chelate metal ions through hydrogen, electron donating and mixed mechanisms (Zhang et al., 2015). Kaempferol have also shown protective effects against oxidative stress through activation of nuclear factor erythroid 2 related factor 2 (Nrf2)-mediated defensive response in lung tissues (Kumar, Kim, More, Kim \& Choi, 2014). Kaempferol glucosides and aglycone have proven to be good inhibitors of intestinal $\alpha$-glucosidase and pancreatic lipase activities (Tan, Chang, \& Zhang, 2017; Zhang et al., 2015). There is also evidence that prodelfinidin dimers are able to bind and inhibit pancreatic lipase activity (Buchholz \& Melzig, 2015). All this information retrieved from the literature support the idea that phenolic compounds identified in F1 are likely contributing to the bioactivity of FLPS.

\subsection{Effect of simulated GD on chemical composition and biological activity of FLPS}

GD extends protein and phenolic chemical modifications and, as consequence, may promote the release of new bioactive compounds and/or degradation of existing ones. Therefore, we studied the modifications induced by simulated GD on chemical composition and biological activities of FLPS (Table 6). GD approximately increased 2-fold the peptide content $(p<0.05)$. These results indicated that new peptides are released by gastrointestinal proteases and peptidases. Similarly, total phenolic content was found 5-fold greater in the FLPS lentil digest $(p<0.05)$. A higher $\mathrm{IC}_{50}$ value was found for ACE-inhibitory activity of the digest suggesting that GD reduced the ACE inhibitory activity of FLPS $(p<0.05)$. We previously observed this effect for lentil hydrolysates produced by Savinase in high-pressure conditions (Garcia-Mora et al., 2015). This loss of activity could be explained by degradation of ACE inhibitory peptides in FLPS by gastrointestinal proteases. Similarly, $\alpha$-glucosidase and lipase inhibitory activities of FLPS were significantly reduced after simulated GD $(p<0.05)$. Our
Table 6

Peptides and total phenolic content and biological activities of bioaccesible (soluble) fraction from FLPS before and after gastrointestinal digestion.

\begin{tabular}{lll}
\hline & Control & Digest \\
\hline Peptides (mg/g) & $229.99 \pm 8.06^{\mathrm{a}}$ & $442.55 \pm 39.39^{\mathrm{b}}$ \\
Phenolics (mg GAE/g) & $65.91 \pm 5.60^{\mathrm{a}}$ & $321.41 \pm 4.85^{\mathrm{b}}$ \\
ACE inhibition (IC $50, \mathrm{mg} / \mathrm{mL})$ & $0.14 \pm 0.01^{\mathrm{a}}$ & $0.23 \pm 0.02^{\mathrm{b}}$ \\
$\alpha$-glucosidase inhibition (\%) & & \\
$\quad$ Sucrase activity & $53.24 \pm 8.72^{\mathrm{a}}$ & $39.41 \pm 2.24^{\mathrm{a}}$ \\
$\quad$ Maltase activity & $38.06 \pm 0.17^{\mathrm{b}}$ & nd \\
Lipase inhibition (\%) & $26.69 \pm 4.12^{\mathrm{b}}$ & nd \\
ORAC (mM TE/g) & $508.78 \pm 48.14^{\mathrm{a}}$ & $556.77 \pm 37.13^{\mathrm{a}}$ \\
Inhibition of ROS generation (\%) & $40.13 \pm 2.48^{\mathrm{a}}$ & $66.58 \pm 1.81^{\mathrm{b}}$ \\
\hline
\end{tabular}

Data are the mean \pm standard deviation of three replicates analyzed in duplicate. Different lowercase letters indicate statistical differences among treatments $(p<0.05$. Duncan's test). GAE: gallic acid equivalents; ACE: Angiotensin I converting enzyme; ORAC: oxygen radical absorbance capacity; ROS: radical oxygen species; nd: not detected.

data suggest that lentil phenolic compounds able to inhibit these enzymes were degraded during GD of FLPS. In this regard, recent studies have demonstrated that $\mathrm{pH}$ changes along GD of common bean chips cause modifications in chemical structure, molecular weight or chemical completion of phenolic compounds (Luzardo-Ocampo et al., 2017). Alternatively, ORAC of FLPS was not affected by GD while inhibition of ROS production was significantly greater after simulated GD $(p<0.05)$. Consistently to results of the present study, we previously observed that GD of lentil antioxidant peptides produced by Savinase released shorter peptide sequences and free amino acids with higher antioxidant activity than the precursor peptides (Garcia-Mora et al., 2017). Other possibility is that the increase in free phenolics observed after GD could also be responsible for the higher protective effect of FLPS to reduce ROS production in $t$ - $\mathrm{BOOH}$-stressed macrophages.

Recent studies have found that bioactivity of foods changes differently along the digestive tract. These changes in bioactivity have been attributed to chemical modifications of bioactive compounds mediated by digestive enzymes, physiological $\mathrm{pH}$ or microbial fermentation (Luzardo-Ocampo et al., 2017). Findings of our study have shown overall compositional and bioactivity changes occurred in FLPS at the end of gastroduodenal digestion although it could not be established whether health-promoting potential of FLPS increased or decreased in previous stages of digestion. Therefore, to overcome the limitations of the present study a quantitative follow-up of biological activity along the whole digestion process would represent a novel approach to understand and predict fermented lentil functionality in vivo.

\section{Conclusions}

In conclusion, the present study demonstrates that FLPS enhanced the overall health potential benefit of lentil in relation to blood pressure, blood glucose absorption, lipid accumulation and oxidative stress. These findings were associated to synergistic effect of Savinase mainly producing bioactive peptides and microbial metabolism mainly responsible for increased concentrations of $p$-hydroxybenzoic acid, vanillic acid and kaempferol glucosides. Fractionation of FLPS and selection of the most multiactive lentil subfraction allowed identifying 30 fragments from convicilin, allergen Len $\mathrm{c} 1$ and lectin as well as the flavonoids prodelphinidin dimer, (+)-catechin-3-O-hexoside, kaempferol rutinoside-hexoside, isorhamnetin glucuronide and kaempferol rutinoside-rhamnoside (II) as the main bioactive compounds. We also determined that GD caused an increase in bioaccessible peptides and phenolics and antioxidant activity. However, losses on ACE-, $\alpha$-glucosidase and lipase inhibitory activities were detected. From these data it can be advised that from a nutraceutical perspective, FPLS would be the most beneficial treatment of commercial production of lentil functional products. This research is unique in the context of lentil functionalization by a pH-controlled fermentative-hydrolytic process and the 
health benefits of FPLS were validated in vivo in a rat model of metabolic syndrome (Martínez et al., 2018).

\section{Acknowledgements}

The research leading to these results received funding from Ministry of Economy and Competitiveness, Spain (MINECO, Spain) and FEDER, European Commision program [grant number AGL2013-43247-R] and Spanish National Research Council, Spain [grant number 201670I044]. E. P. acknowledges to MINECO and European Social Fund for her "Ramón y Cajal" contract.

\section{Conflicts of interest}

The authors declare no conflict of interest.

\section{Appendix A. Supplementary data}

Supplementary data associated with this article can be found, in the online version, at http://dx.doi.org/10.1016/j.foodchem.2018.03.044.

\section{References}

Al Shukor, N., Van Camp, J., Gonzales, G. B., Staljanssens, D., Struijs, K., Zotti, M. J., ... Smagghe, G. (2013). Angiotensin-converting enzyme inhibitory effects by plant phenolic compounds: A study of structure activity relationships. Journal of Agricultural and Food Chemistry, 61(48), 11832-11839.

Buchholz, T., \& Melzig, M. F. (2015). Polyphenolic compounds as pancreatic lipase inhibitors. Planta Medica, 81, 771-783.

Dueñas, M., Martínez-Villaluenga, C., Limón, R. I., Peñas, E., \& Frias, J. (2015). Effect of germination and elicitation on phenolic composition and bioactivity of kidney beans. Food Research International, 70, 55-63.

Esteban-Torres, M., Landete, J. M., Reverón, I., Santamaría, L., de las Rivas, B., \& Muñoz, R. (2015). A Lactobacillus plantarum esterase active on a broad range of phenolic esters. Applied and Environmental Microbiology, 81, 3235-3242.

Filannino, P., Di Cagno, R., \& Gobbetti, M. (2018). Metabolic and functional paths of lactic acid bacteria in plant foods: Get out of the labyrinth. Current Opinion in Biotechnology, 49, 64-72.

Finer, N., James, W. P., Kopelman, P. G., Lean, M. E., \& Williams, G. (2000). One-year treatment of obesity: A randomized, double-blind, placebo-controlled, multicentre study of orlistat, a gastrointestinal lipase inhibitor. International Journal of Obesity and Related Metabolic Disorders, 24, 306-313.

Garcia-Mora, P., Frias, J., Peñas, E., Zielinski, H., Gimenez-Bastida, J. A., Wiczkowski, W., \& Martinez-Villaluenga, C. (2015). Simultaneous release of peptides and phenolics with antioxidant, ACE-inhibitory and anti-inflammatory activities from pinto bean (Phaseolus vulgaris L. var. pinto) proteins by subtilisins. Journal of Functional Foods, 18, 319-332.

Garcia-Mora, P., Martín-Martínez, M., Angeles Bonache, M., González-Múniz, R., Peñas, E., Frias, J., \& Martinez-Villaluenga, C. (2017). Identification, functional gastrointestinal stability and molecular docking studies of lentil peptides with dual antioxidant and angiotensin I converting enzyme inhibitory activities. Food Chemistry, 221, 464-472.

Garcia-Mora, P., Peñas, E., Frias, J., \& Martinez-Villaluenga, C. (2014). Savinase, the most suitable enzyme for releasing peptides from lentil (Lens culinaris var. Castellana) protein concentrates with multifunctional properties. Journal of Agricultural and Food Chemistry, 62, 4166-4174.

Gericke, B., Schecker, N., Amiri, M., \& Naim, H. Y. (2017). Structure-function analysis of human sucrase-isomaltase identifies key residues required for catalytic activity. Journal of Biological Chemistry, 292, 11070-11078.

Hafeez, Z., Cakir-Kiefer, C., Roux, E., Perrin, C., Miclo, L., \& Dary-Mourot, A. (2014). Strategies of producing bioactive peptides from milk proteins to functionalize fermented milk products. Food Research International, 63, 71-80.

Hur, S. J., Lee, S. Y., Kim, Y.-C., Choi, I., \& Kim, G.-B. (2014). Effect of fermentation on the antioxidant activity in plant-based foods. Food Chemistry, 160, 346-356.

Ibrahim, M. A., Bester, M. J., Neitz, A. W. H., \& Gaspar, A. R. M. (2017). Structural properties of bioactive peptides with $\alpha$-glucosidase inhibitory activity. Chemical
Biology and Drug Design Article in Press.

Jakubczyk, A., Karas, M., Zlotek, U., \& Szymanowska, U. (2017). Identification of potential inhibitory peptides of enzymes involved in the metabolic syndrome obtained by simulated gastrointestinal digestion of fermented bean (Phaseolus vulgaris L.) seeds. Food Research International, 100, 486-496.

Jew, S., Abuweis, S. S., \& Jones, P. J. H. (2009). Evolution of the human diet: Linking our ancestral diet to modern functional foods as a means of chronic disease prevention. Journal of Medicinal Food, 12, 925-934.

Kim, Y. S., Lee, Y. M., Kim, H., Kim, J., Jang, D. S., Kim, J. H., \& Kim, J. S. (2010). Antiobesity effect of Morus bombycis root extract: Anti-lipase activity and lipolytic effect. Journal of Ethnopharmacology, 130, 621-624.

Kleerebezem, M., Boekhorst, J., Van Kranenburg, R., Molenaar, D., Kuipers, O. P., Leer, R., ... Siezen, R. J. (2003). Complete genome sequence of Lactobacillus plantarum WCFS1. Proceedings of the National Academy of Sciences of the United States of America, 100, 1990-1995.

Kumar, H., Kim, I.-S., More, S. V., Kim, B.-W., \& Choi, D.-K. (2014). Natural productderived pharmacological modulators of Nrf2/ARE pathway for chronic diseases. Natural Products Report, 31, 109-139.

Lee, S. Y., \& Hur, S. J. (2017). Antihypertensive peptides from animal products, marine organisms, and plants. Food Chemistry, 228, 506-517.

Li, Y. W., \& Li, B. (2013). Characterization of structure-antioxidant activity relationship of peptides in free radical systems using QSAR models: Key sequence positions and their amino acid properties. Journal of Theoretical Biology, 318, 29-43.

Limon, R. I., Peñas, E., Torino, M. I., Martínez-Villaluenga, C., Dueñas, M., \& Frias, J. (2015). Fermentation enhances the content of bioactive compounds in kidney bean extracts. Food Chemistry, 172, 343-352.

Lv, H., Liu, Q., Zhou, J., Tan, G., Deng, X., \& Ci, X. (2017). Daphnetin-mediated Nrf2 antioxidant signaling pathways ameliorate tert-butyl hydroperoxide (t-BHP)-induced mitochondrial dysfunction and cell death. Free Radical Biology and Medicine, 106, 38-52.

Luzardo-Ocampo, I., Campos-Vega, R., Gaytán-Martínez, M., Preciado-Ortiz, R., Mendoza, S., \& Loarca-Piña, G. (2017). Bioaccessibility and antioxidant activity of free phenolic compounds and oligosaccharides from corn (Zea mays L.) and common bean (Phaseolus vulgaris L.) chips during in vitro gastrointestinal digestion and simulated colonic fermentation. Food Research International, 100, 304-311.

Martín, M. A., Cordero-Herrera, I., Bravo, L., Ramos, S., \& Goya, L. (2014). Cocoa flavanols show beneficial effects in cultured pancreatic beta cells and liver cells to prevent the onset of type 2 diabetes. Food Research International, 63, 400-408.

Martínez, R., Kapravelou, G., Donaire, A., Lopez-Chaves, C., Arrebola, F., Galisteo, M., ... López-Jurado, M. (2018). Effects of a combined intervention with a lentil protein hydrolysate and a mixed training protocol on the lipid metabolism and hepatic markers of NAFLD in Zucker rats. Food and Function, 9, 830-850.

Mojica, L., Luna-Vital, D. A., \& González de Mejía, E. (2017). Characterization of peptides from common bean protein isolates and their potential to inhibit markers of type-2 diabetes, hypertension and oxidative stress. Journal of the Science of Food and Agriculture, 97, 2401-2410.

Simsek, M., Quezada-Calvillo, R., Feruzzi, M. G., Nichols, B. L., \& Hamaker, B. R. (2015). Dietary phenolic compounds selectively inhibit the individual subunits of maltaseglucoamylase and sucrase-isomaltase with the potential of modulating glucose release. Journal of Agricultural and Food Chemistry, 63, 3873-3879.

Singh, B. P., \& Vij, S. (2017). Growth and bioactive peptides production potential of Lactobacillus plantarum strain C2 in soymilk: A LC-MS/MS based revelation for peptides biofunctionality. LWT - Food Science and Technology, 86, 293-301.

Tan, Y., Chang, S. K. C., \& Zhang, Y. (2017). Comparison of $\alpha$-amylase, $\alpha$-glucosidase and lipase inhibitory activity of the phenolic substances in two black legumes of different genera. Food Chemistry, 214, 259-268.

Torino, M. I., Limón, R. I., Martínez-Villaluenga, C., Mäkinen, S., Pihlanto, A., VidalValverde, C., \& Frias, J. (2013). Antioxidant and antihypertensive properties of liquid and solid state fermented lentils. Food Chemistry, 136, 1030-1037.

Xuan, C. L., Yao, F. R., Guo, L. R., Liu, Q., Chang, S. K., Liu, K. X., \& Sun, C. W. (2013). Comparison of extracts from cooked and raw lentil in antagonizing angiotensin IIinduced hypertension and cardiac hypertrophy. European Review for Medical and Pharmacological Sciences, 17, 2644-2653.

Vilcacundo, R., Martínez-Villaluenga, C., \& Hernández-Ledesma, B. (2017). Release of dipeptidyl peptidase IV, $\alpha$-amylase and $\alpha$-glucosidase inhibitory peptides from quinoa (Chenopodium quinoa Willd.) during in vitro simulated gastrointestinal digestion. Journal of Functional Foods, 35, 531-539.

World Health Organization (2014). Global status report on non-communicable diseases Genève, Switzerland: World Health Organization280.

Zhang, B., Deng, Z., Ramdath, D. D., Tang, Y., Chen, P. X., Liu, R., ... Tsao, R. (2015). Phenolic profiles of 20 Canadian lentil cultivars and their contribution to antioxidant activity and inhibitory effects on $\alpha$-glucosidase and pancreatic lipase. Food Chemistry, $172,862-872$. 